\title{
Ga-68 NeoBOMB1 PET/MRI Positron Emission Tomography and Magnetic Resonance Imaging
}

National Cancer Institute

\section{Source}

National Cancer Institute. Ga-68 NeoBOMB1 PET /MRI Positron Emission Tomography and Magnetic Resonance Imaging. NCI Thesaurus. Code C154293.

An imaging procedure that combines gallium-68-labelled NeoBomb1 PET with an MRI scan to overlay activity data onto detailed anatomic images. 